\title{
China announces plans to fast-track drug approval
}

Policies are expected to speed up access to medicines and boost the country's pharmaceutical industry.

\section{David Cyranoski}

\section{October 2017}
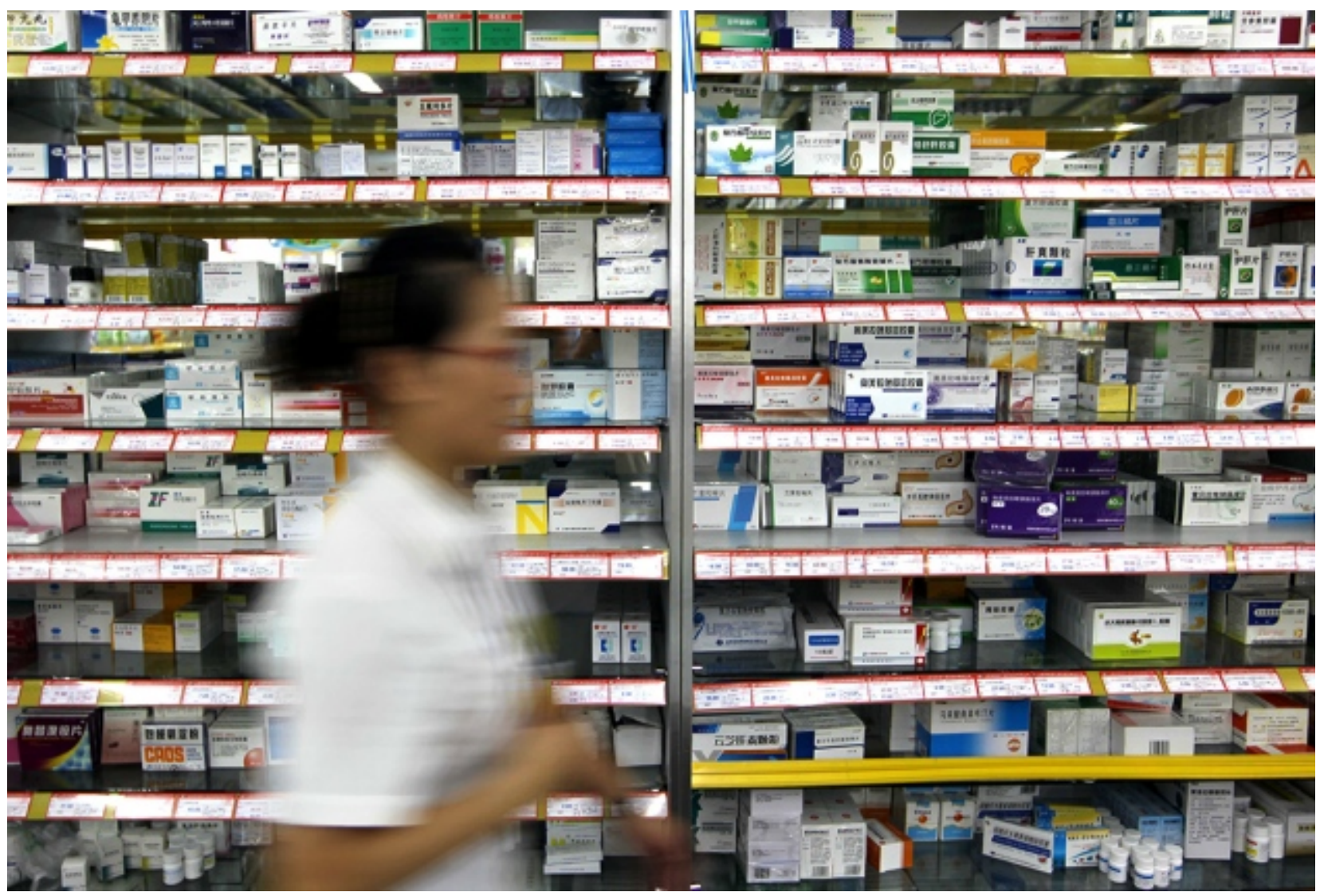

Xue Jun/Xinhua via ZUMAPRESS

China is aiming to cut the amount of time people have to wait for new medicines.

China is overhauling its drug-approval system to let companies bring their treatments to market quicker and more easily. On 9 October, the Communist Party of China and the State Council, two of the country's most authoritative bodies, announced plans to reduce the backlog of medicines awaiting approval by the China Food and Drug Administration (CFDA). Policies will also be introduced to boost the productivity of Chinese drugmakers and spur innovation in health care. 
Details of the plans are only just starting to emerge, but industry observers expect them to be in place by the end of 2017. One proposal, released for public comment on 20 October, states that companies will be allowed to use data from clinical trials conducted in other countries when applying for drug approval in China. Currently, companies have to perform extra trials in China to test a drug's efficacy. Under the new guidelines, they will instead need to provide data that show that a drug works in all human populations.

The changes will significantly reduce the time Chinese people have to wait for new medicines, and will save multinational companies time and money, says Angela Yan, senior director of science and regulatory affairs at the R\&D-based Pharmaceutical Association Committee in Beijing, which represents the interests of foreign companies in China. A vaccine against the human papillomavirus, for example, was approved in China only in 2016, a decade after it was given the green light in the United States. More than 20 years of efforts to reduce delays are now paying off, says Yan. "This is very positive."

\section{Unblocking the pipeline}

The shake-up is the latest in a series of measures to accelerate China's drug-regulation process and make it more rigorous, in line with international standards. In the past two years, the government has dramatically increased the number of application inspectors at the CFDA to reduce the backlog of medicines awaiting approval. It has also threatened to jail manufacturers

\section{Related stories}

- China cracks down on fake data in drug trials

- China embraces precision medicine on a massive scale

- China drugs head fired over article row

More related stories

\section{Related stories}

- China cracks down on fake data in drug trials

- China embraces precision medicine on a massive scale

- China drugs head fired over article row

More related stories or researchers caught submitting fraudulent applications.

And in June, China became a member of the International Council for Harmonisation of Technical Requirements for Pharmaceuticals for Human Use, which requires a nation's drug-approval agency to adhere to international standards and guidelines. 
As well as reducing the administrative burden of drug registration, the government is eager to expand its pharmaceutical industry, given that China is the world's second largest drug market. Between 2001 and 2016, China approved just over 100 new drugs, whereas developed countries approved 433.

\section{Far-reaching policies}

Su Ling, director of the Institute of Drug Regulatory Science at Shenyang Pharmaceutical University and a venture partner for the investment fund Lilly Asia Ventures in Shanghai, says the government will introduce a range of policies that will have broad effects on the industry. "Overall they are in the right direction to become more aligned with international norms and to promote new drug R\&D and access," says Su. "This is really important."

Another policy, announced by the CFDA on 10 October, will end the restriction that prohibits pharmaceutical companies from starting phase I safety trials for a drug in China until its safety has been proved in another country. The ban was designed to protect Chinese people from exploitation by drug companies during early experiments.

Yan says loosening the restriction could plug crucial holes in China's drug-development pipeline, which has lost capacity to translate research from animals to humans. "Now they can do global phase I trials and learn and improve their capabilities," she says.

Nature doi: $10.1038 /$ nature.2017.22888 